\title{
MARTÍN SARMIENTO, EL BENEDICTINO GALLEGO QUE EN REPETIDAS OCASIONES RECHAZÓ LAS OFERTAS DEL REY
}

\author{
POR \\ JOSÉ SANTOS PUERTO \\ Universidad de La Laguna
}

RESUMEN:

En este artículo se recuerdan algunas actividades y nombramientos del benedictino Martín Sarmiento. Conoceremos detalles sobre su elección en 1748 para la abadía del monasterio de San Martín de Madrid, su casa de profesión. Indagaremos las razones que le llevaron a no querer cobrar los sueldos inherentes al título de cronista general de Indias, que le fue concedido por Fernando VI en 1750. Y averiguaremos cómo fue designado por el Rey abad de Ripoll en 1755 y por qué renunció al año siguiente.

PALABRAS CLAVE: Martín Sarmiento. Ilustración española. Cronista General de Indias. Abadías Benedictinas. Monasterio de Ripoll.

\section{MARTIN SARMIENTO, THE GALICIAN BENEDICTINE WHO REPEATEDLY REJECTED THE OFFERS OF THE KING}

\section{ABSTRACT:}

In this article we review some activities and appointments of Martín Sarmiento, Benedictine monk of the Saint Martin's Abbey in Madrid. We will know details on his election in 1748 for the abbey of the monastery. We will investigate the reasons that led him not to accept the inherent salaries in the title of Cronista General de Indias, who was granted to him by Fernando VI in 1750. And also we will verify how it was designated by the king abbot of Ripoll in 1755 and why he resigned on the following year.

KEYWORDS: Martin Sarmiento. Spanish Enlightenment. The General Chronicler of Indies. Benedictine Abbeys. Monastery of Ripoll. 


\section{Recibido/Received 01-04-2011 Aceptado/Accepted 04-05-2012}

Martín Sarmiento, el Gran Gallego, testigo de su siglo y principal representante de la utopía en las Españas de la llustración ${ }^{1}$, es bastante conocido y apreciado en Galicia, en donde las instituciones de aquella comunidad le han tributado varios homenajes en las últimas décadas. ${ }^{2}$ En el resto de España también se ha revalorizado su figura en algunas de las muchas vertientes a las que le acercó su curiosidad investigadora. ${ }^{3}$

Aunque nos dejó abundantes noticias personales intercaladas en sus escritos y en los diarios de sus viajes que hoy sirven para investigar y reconstruir parte de su biografía, ${ }^{4}$ algunas circunstancias de su vida resultan no obstante curiosas y polémicas, pues siendo el primero que sentó las bases para buscar la partida de bautismo de Cervantes en Alcalá de Henares, la suya no se ha podido encontrar y por eso se le atribuyen varias patrias y lugares de nacimiento. ${ }^{5}$

Tampoco son muy conocidos los empleos y actividades derivadas de su condición de monje benedictino. De algunos de esos cargos y nombramientos nos vamos a ocupar en este artículo, deteniéndonos particularmente en su elección como abad de San Martín de Madrid, de cronista general de Indias, y de abad mitrado del monasterio de Ripoll. Aunque se trata de noticias ya

${ }^{1}$ López Peláez, A. 1895. El Gran Gallego. La Coruña: Andrés Martínez. Pensado Tomé, J.L. 1972. Fr. Martín Sarmiento, testigo de su siglo. Salamanca: Universidad de Salamanca. Santos Puerto, J. 2002. Martín Sarmiento: Ilustración, educación y utopía en la España del s. XVIII. La Coruña: Fundación Barrié de la Maza.

2 VV.AA. 1995. Estudos adicados a Fr. Martín Sarmiento. Santiago de Compostela: Instituto de Estudios Gallegos Padre Sarmiento y CSIC. VV.AA. O Padre Sarmiento e o seu tempo. 1997. Santiago de Compostela: Universidad y Consello da Cultura Galega. Santamarina, A. (coord). 2002. Frei Martín Sarmiento. Día das letras galegas 2002. Santiago de Compostela: Universidad.

${ }^{3}$ Pensado Tomé, J.L. 1960. Fray Martín Sarmiento. Sus ideas lingüísticas. Oviedo: Universidad de Oviedo. Filgueira Valverde, J. 1981. Ideas y sistema de la historia en Fr. Martín Sarmiento. Madrid: Real Academia de la Historia. Allegue Aguete, P. 1993. A filosofía ilustrada de fr. Martín Sarmiento. Vigo: Xerais. Costa, A. y Álvarez, M. 2002. Martín Sarmiento. La educación de la niñez y de la juventud [textos]. Madrid: Biblioteca Nueva. Monteagudo, H. 2002. Martín Sarmiento, Sobre a lingua galega. Antoloxía. Vigo: Galaxia. Pardo de Guevara, E. 2002. Fr. Martín Sarmiento, el amador de la verdad (1695-1772). A Coruña: Diputación Provincial. Reguera, A.T. 2006. La obra geográfica de Martín Sarmiento. León: Universidad de León. Varela Oriol, C. 2011. "Martín Sarmiento y las bibliotecas de la congregación benedictina de Valladolid". Hispania 237: 121-152.

${ }^{4}$ Jurado Jiménez, D. 2011. "El diario como instrumento de autoformación e investigación". Qurriculum 24: 173-200.

5 Santos Puerto, J. 2010. "Acerca de la naturaleza y de la patria del P. Sarmiento". Sarmiento 14: 125-131. 
OCASIONES RECHAZÓ LAS OFERTAS DEL REY

conocidas, algunos documentos y correspondencia recientemente publicados nos proporcionan nuevos matices y puntos de vista dignos de reseñar. Se trata, principalmente, de cartas enviadas por Sarmiento a Francisco Roca, procurador general de la congregación benedictina en Roma, entre mayo de 1749 y junio de 1756, que sirven, con el sesgo de la subjetividad de una correspondencia personal para mejor conocer esos tres momentos clave de la vida de Sarmiento.

El ABAD de SAN MARTín Que DEJó dE SERLO POR UN DERECHO ENTENDIDO AL REVÉS

Siguiendo el ejemplo de los movimientos de reforma europeos, e impulsados por la Corona, la mayor parte de los monasterios benedictinos españoles se adhirieron a principios del siglo XVI a la congregación de San Benito de Valladolid, consiguiendo así recobrar nuevo vigor espiritual y material. Uno de esos monasterios reformados era el de Santo Domingo de Silos, que ingresó en la congregación vallisoletana en 1512, incorporando también su priorato de San Martín de Madrid, cenobio mozárabe que había comenzado a depender de Silos durante el reinado de Alfonso VI. ${ }^{6}$

En tiempos de Felipe II pareció conveniente transformar a San Martín en abadía independiente, lo que a instancias del Rey se aprobó en el capítulo general benedictino celebrado en 1592 y después concedió el Papa Clemente VIII en 1594. Silos protestó y entabló pleito que pareció tener solución tras la reunión del capítulo celebrado en 1601. El acuerdo, confirmado por bula del mismo Clemente VIII en 1603, señalaba a San Martín como abadía propia, obligándose a mantener a cuatro monjes de Silos y cediendo a su favor algunos derechos en la elección del abad en alternancia con la congregación.

En el capítulo general de 1661 se rompió el acuerdo y se votó la supresión de la alternancia, que fue refrendada por bula de Alejandro VII de 11 de octubre de 1662. Esta decisión fue impugnada a su vez por Silos ante la nunciatura, y como en 1664 ésta falló a su favor, la bula de 1662 no fue ejecutada. En el capítulo de 1709 la congregación decidió recurrir al Tribunal de la Rota por medio del general entrante, Pedro Magaña, solicitando que San Martín pasara a ser independiente de Silos. ${ }^{7} \mathrm{Y}$ para tener más argumentos a favor, el capítulo incidió en la necesidad de favorecer la toma de hábitos en el monasterio madrileño, que por aquella época contó con una docena de nuevos monjes. Es en ese contexto de revitalización de la independencia de San Martín frente a Silos en el que debemos encuadrar la llegada a Madrid

${ }^{6}$ Maté Sadornil, L. 2003. "Silos dentro de la Congregación Benedictina de Valladolid en los siglos XVI-XVIII", en Silos: un milenio, vol. 2, 297-320. Burgos: Universidad de Burgos.

7 Relación detallada del pleito entre Silos y San Martín en Archivo Histórico Nacional, Clero Secular Regular, L, 10352, fol. 61-63. 
del joven gallego Martín Sarmiento (entonces aún Pedro García), que ingresó en el monasterio madrileño en 1710 y profesó al año siguiente.

El Tribunal de la Rota resolvió el 16 de marzo de 1711 a favor de San Martín. La decisión fue discutida nuevamente en la reunión capitular de 1713, pero como Silos volvió a protestar y no había entonces monjes profesos en San Martín que pudiesen reclamar su derecho preferente a la abadía, se optó por dejar las cosas como estaban antes.

Un par de décadas después había varios hijos de San Martín con méritos suficientes para hacerse cargo de la abadía, entre otros Martín Sarmiento, que desde 1733 tenía voto en el capítulo por haber sido designado cronista de la congregación en sustitución del fallecido Bernabé Iguin. ${ }^{8}$ Ese nombramiento como cronista derivaba de su interés y vinculación con la actividad histórica y archivística, como se había puesto de manifiesto en la catalogación del archivo y biblioteca de la catedral de Toledo y en sus propuestas de crear un cuerpo de archiveros, copistas y traductores de los manuscritos de la orden benedictina. Pero ni Sarmiento ni otros compañeros de San Martín tuvieron interés por hacerse con la abadía hasta varios años después, cuando un hecho luctuoso vino a perturbar aquella aquiescente actitud.

En 1745 había sido elegido abad de San Martín un monje de Silos, Sebastián de Vergara, que falleció el 6 de abril de 1748. En caso de fallecimiento del abad durante su mandato las Constituciones vigentes establecían que el sustituto sería elegido por mayoría en votación realizada por el general de la congregación, el abad de la casa en donde el general hubiera recibido la noticia y los tres definidores del distrito. ${ }^{9}$

De acuerdo con las normas señaladas en las Constituciones, el día 22 de abril se reunieron el general y los definidores, que de forma unánime decidieron elegir como nuevo abad a Sarmiento. El general y los definidores no ignoraban que el monasterio de Silos pondría reparos, reclamando para sí el derecho de elección ya que el fallecido Sebastián de Vergara había sido nombrado por el turno de Silos, pero según señalaba Sarmiento en escrito dirigido a la nunciatura, los electores razonaron de este modo: ¿San Martín es filiación de Silos o no? Si es filiación de Silos, los profesos de San Martín pertenecen a Silos y podrán ser abades no sólo de San Martín sino también de la abadía burgalesa; y si fuera monasterio independiente, los profesos de San Martín que cumpliesen con los requisitos tendrían derecho a ser abades de su casa como los demás monjes a serlo de las suyas.

El 28 de abril de 1748 Sarmiento tomó posesión de la abadía con la conformidad de todos los monjes presentes en San Martín. Y su

${ }^{8}$ Zaragoza Pascual, E. 1992. "Cronistas generales de la congregación de San Benito de Valladolid". Boletín de la Real Academia de la Historia 189: 89-126.

9 1706. Constituciones de la Congregación de nuestro glorioso padre san Benito de España e Inglaterra: Libro I, Capítulo XXVII. Madrid: Viuda de Melchor Álvarez. 
OCASIONES RECHAZÓ LAS OFERTAS DEL REY

nombramiento no sólo fue bien recibido entre algunos miembros de su orden, sino también en la sociedad civil madrileña, como se ve en la relación de visitas que le hicieron cuando comenzó su abadía. ${ }^{10}$ El 8 de mayo, en calidad de abad, convocó por primera vez al consejo del monasterio, lo que continuó haciendo hasta el 17 de abril del año siguiente como consta en las actas. ${ }^{11}$

El monasterio de Silos no se conformó y recurrió la elección, por lo que el nuncio solicitó el parecer de Sarmiento, y de ahí deriva la exposición a la que antes aludimos. Sarmiento daba cuenta en su escrito de la sorpresa que le producía la reclamación de Silos en contra de su derecho, entendiendo que una cosa era el pleito que mantenían Silos y la Congregación sobre la alternancia de San Martín y otra la preferencia y el derecho de los profesos de su monasterio a ser abades en caso de ser elegidos para ello, cumpliendo las condiciones prescritas en las Constituciones. ${ }^{12}$ Señala Sarmiento que tanto él como otros profesos del monasterio de San Martín cumplen las condiciones desde 1729, aunque ninguno se interesó por la abadía ni reclamó sus derechos de preferencia, porque estaban "más interesados en vivir tranquilos y en paz que en ser abades por pleito". ${ }^{13}$

Expone también que no iba a personarse como representante del monasterio en el pleito entablado por Silos en la nunciatura, porque eso supondría sembrar la discordia en el claustro, en donde había tres clases de conventuales: profesos de Silos, a los que él no iba a pedir poderes (ni ellos deberían darlos) para seguir pleito en contra de su monasterio de origen; monjes profesos en otros monasterios, residentes temporalmente en Madrid con permiso de la orden, quienes no deberían tomar parte en la disputa, y en caso de hacerlo tendrían que atenerse a lo acordado por la congregación; y por último, los profesos de San Martín, que eran cinco aunque en aquellas fechas solamente él y otros dos más residían en Madrid. En todo caso,

${ }^{10}$ Sarmiento, M. Visitas que me hicieron cuando entré por abad a 28 de Abril de 1748. Biblioteca Universitaria de Santiago, Mss. 599/2. Es relación detallada, escrita por el benedictino, de personalidades que le visitaron para felicitarle con motivo de su nombramiento como abad.

${ }^{11}$ Libro de Actas del Consejo de este Monasterio de San Martín de Madrid. Biblioteca Nacional de España, Madrid, Mss.13284. Es documentación fundamental para la biografía de Martín Sarmiento, ya que en las actas de su toma de hábito en 19 de mayo de 1710 y de profesión en 15 de abril de 1711 quedó recogido que era natural de San Juan de Zercedo, en Galicia, y no de Villafranca del Bierzo, como se ha venido sosteniendo desde poco después de su muerte.

12 En aquella época para ser elegido abad había una primera exigencia de antigüedad: 15 años de hábito y 12 años de estudios. Se exigía también experiencia previa en oficios relacionados con el gobierno del monasterio o de la orden. $Y$ en igualdad de condiciones deberían ser preferidos los profesos de las casas respectivas. Cf. Constituciones de la Congregación, Libro I, Cap. IX, X y XI.

${ }^{13}$ Archivo de Silos, Mss. 114. Es una copia, con firma autógrafa de Sarmiento al final del documento, de la exposición entregada por fray Martín en la nunciatura a primeros de julio de 1748. 
Sarmiento entendía que aquella cuestión debería ventilarse dentro de la religión benedictina y no en otros tribunales eclesiásticos.

Sabíamos, por las actas del capítulo celebrado en 1749, que Silos se salió con la suya y que en la reunión capitular se anuló la elección de Sarmiento ${ }^{14}$, de modo que Melchor Izquierdo, monje de Silos, figura hoy como abad entre 1748-49, siendo así que en ese tiempo no tenía residencia en Madrid ni aparece en las actas como miembro del consejo. Desde la publicación de la correspondencia con el Duque de Medinasidonia también sabíamos cómo decía sentirse Sarmiento después del ultraje al que había sido sometido en Valladolid en la reunión del capítulo de 1749: "viviré vanaglorioso de haber sido el único del mundo para cuya tropelía se inventó un nuevo derecho al revés, de preferir a los hijos propios legítimos de una madre, los extraños y en nada parientes". ${ }^{15} \mathrm{Y}$ días más tarde insistía en ese punto y precisaba:

"Con razón me llama gato de desván el Sr. Conde de Maceda, pues apenas me hostigaron para que saliese a público, y de mi desván a la calle, cuando comencé a ser el negro de la envidia y el blanco de las piedras de todo mal intencionado (...) lo que irritó la envidia no ha sido otra cosa que aquel aprecio con que a algunos personajes se les ha antojado hacer de mi persona (...) libros, aprecio y empleo han sido los tres enemigos de mi honor y los tres torcedores de la envidia (...) No quiero más empleo que el que merece el alma de Garibay; no quiero más comunicaciones ni aprecios que los que tiene un gato de desván; ni tampoco quiero más libros (...) de ese modo daré gusto a los envidiosos y ambiciosos, y vivirán sosegados, viendo que jamás les podré servir de estorbo". ${ }^{16}$

En la correspondencia mantenida con Francisco Roca, procurador de la congregación en Roma existe una carta fechada el mismo día que la remitida a Medinasidonia, en la que Sarmiento nos da una visión parecida de su estado de ánimo y de su determinación de tener una vida más retirada en su celda. Pero también nos proporciona algunos detalles de los entresijos eclesiásticos y monásticos que propiciaron la decisión de la nunciatura, que después había adoptado la congregación en la reunión capitular de Valladolid.

Nuestro monje le dice a Roca que durante el año que duró su mandato de abad no se había preocupado apenas del pleito que mantenían Silos y la congregación, sino de ayudar a los pobres de Madrid y estar en paz con los monjes. En abril había salido para el capítulo de Valladolid sin enterarse de que la nunciatura había decidido anular su elección.

14 Zaragoza Pascual, E. 1984. Los Generales de la Congregación de San Benito de Valladolid (1701-1801): 158. Silos: Abadía de Silos,.

${ }^{15}$ Sarmiento, M. 1995. Cartas al Duque de Medinasidonia, edición de Santos Puerto, J. Ponferrada: Instituto de Estudios Bercianos. Carta de 18/05/1749.

16 Ibídem. Carta de 24/05/1749. 
OCASIONES RECHAZÓ LAS OFERTAS DEL REY

"Salí sin saber que en la Nunciatura, y en Valladolid, me estaban asesinando. Apenas salí, cuando por auto del Sr. auditor, se notificó a esta comunidad que yo no había sido verdadero abad; que no debía votar como abad, sino como cronista; y que el P. Prior Berganza fuese a Valladolid a votar como presidente de San Martín. Al mismo tiempo que llegué allí, me hallé sorprendido con aquel embarazo, siendo así que el auto se había dado el día 28 de marzo, y ocho días antes que yo saliese ya Berganza tenía oculta la carta del $P$. Secretario para que fuese a Valladolid, y su fecha a 23 de abril, el mismo día que el Rvdmo. General recibió informe de abogado de Madrid, de que no debía ser tal presidente". 17

Sarmiento tenía intención de presentarse nuevamente para la abadía, haciendo valer los derechos de preferencia de los profesos de San Martín. Pero aquella decisión de la nunciatura y del capítulo se lo impedía, ya que las Constituciones vigentes señalaban que no podía ser abad quien hubiera sido privado de la abadía en el cuatrienio anterior. ${ }^{18}$ Por eso en la reunión capitular hubo particular empeño en invalidar su elección del año anterior y en elegir por abad a un monje de Silos con la condición de que renunciase a los cuatro días.

A él, como ya conocíamos por la correspondencia con Medinasidonia, le dieron un nombramiento honorífico de "general pasado", que no le satisfacía en absoluto. En la correspondencia con el procurador general Roca insiste en ese punto: "Para hacer más ruidosa la infamia (...) allá, no sé quiénes, amañaron que me diesen los honores de general pasado, para que sobresaliesen más en la contradicción los honores de no haber sido pasado abad, y por sentencia seria, ni siquiera por un año que ya se había cumplido". ${ }^{19}$ Igual que había expuesto a Medinasidonia, también a Roca le manifestaba su deseo de recluirse en su celda, para no ser el blanco de los envidiosos:

17 Santos Puerto, J. 2010. "Correspondencia inédita y otras contribuciones para ampliar el Epistolario de Martín Sarmiento". Cuadernos de Estudios Gallegos 123: 319-356. Carta de Sarmiento a Francisco Roca, procurador benedictino en Roma, de 24/05/1749.

No sabemos en qué fecha exacta salió Sarmiento para Valladolid. Lo que sí sabemos por las actas del consejo del monasterio es que Tomás Berganza, en calidad de presidente por ausencia de Sarmiento, convocó al consejo el día 29 de abril para elegir nuevo presidente en su propia ausencia, por pasar al capítulo de Valladolid como se le indicaba en la carta que le había remitido el general Plácido Cortada. Libro de Actas del Consejo de este Monasterio de San Martín..., citado, fol. 341.

${ }^{18}$ Constituciones de la Congregación, Libro I, Capítulo X, § 4. Tampoco podía ser abad quien lo hubiera sido durante la mayor parte del cuatrienio anterior. Ese no era el caso de Sarmiento, que sólo lo había sido durante un año.

${ }^{19}$ Santos Puerto, J. 2010: 343. 
Si el $\mathrm{Em}^{\circ}$ [cardenal Valenti] volviera a preguntarle por mí y le dijera por qué no escribo -le decía a Roca- responderá a su $\mathrm{Em}^{\mathrm{a}}$ lo que gustare (...) pero certificándole que viéndome abandonado de todos, con tanta infamia e injusticia, quiero dar gusto a todos, abandonándome a mí mismo y abandonando todo comercio de palabra y por escrito, para que mis envidiosos vivan sosegados y me dejen en paz.

$Y$ ya desde entonces comenzaron a rondar por su cabeza las ideas que luego plasmaría en El Por qué Sí y el Por qué No. Por eso en su carta a Francisco Roca le orientaba sobre posibles respuestas al cardenal Valentí Gonzaga: "dígale que soy un fraile ridículo; que o no recibo o no respondo a cartas; que soy grosero, insociable y gato de desvanes; y todo lo que se le viniere a la boca, pues para todo doy licencia". ${ }^{20}$

Una cosa es el deseo de Sarmiento de recluirse, como gato de desvanes, y otra es que sus amistades se lo permitieran. $Y$ amigos tenía entonces muchos, y algunos con bastante influencia en el entorno del Rey, como Carvajal, Medinasidonia y Rávago; o como los encargados de las obras del palacio en construcción: Elgueta, Sachetti, Felipe de Castro. Por eso no tuvo tiempo para encerrarse, ya que le pidieron varios informes para distribuir los adornos y estatuas del palacio conforme al sistema que él había ideado en 1747, proyecto artístico y decorativo, a la vez que histórico y didáctico, de legitimación de la presencia de los Borbones en el trono español, presentados como dinastía continuadora de una misma identidad nacional. ${ }^{21}$ Eso puede explicar el empeño que puso Fernando VI en nombrarle cronista de Indias a la muerte de Miguel Herrero en 1750.

\section{El CRONISTA DE INDIAS QUE NO QUISO EJERCER EL EMPLEO POR SER OFICIO DE JORNAL}

Como es de sobra conocido, la Real Academia de la Historia tiene sus orígenes en la tertulia que se reunía en la casa de Julián de Hermosilla y que a partir de 1736 pasó a tener lugar en una sala de la Biblioteca Real. Sabido es también que en abril de 1738 Felipe $\vee$ elevó aquella incipiente institución de sociabilidad a la condición de Academia de la Historia, por lo que en junio de ese mismo año se despachó la cédula fundacional, que incluía los primeros estatutos y comenzó dirigiendo Agustín Montiano y Luyando. ${ }^{22}$

\section{0 ídem.}

${ }^{21}$ Álvarez Barrientos, J. y Herrero, C. 2002. Sistema de adornos del Palacio Real de Madrid. Madrid: Conmemoraciones Culturales. Muniaín Ederra, S. 2000. El Programa escultórico del Palacio Real de Madrid y la llustración Española. Madrid: Fundación Universitaria Española.

${ }^{22}$ Velasco Moreno, E. 2000. La Real Academia de la Historia en el siglo XVIII: una institución de sociabilidad. Madrid: Centro de Estudios Políticos y Constitucionales. Rumeu de Armas, A. 2001. La Real Academia de la Historia. Madrid: Real Academia de la Historia. 
OCASIONES RECHAZÓ LAS OFERTAS DEL REY

Al poco tiempo se hizo patente la escasez de recursos económicos y materiales para mantener los objetivos de la recién creada institución, por lo que el director hizo uso de su influencia en los círculos reales para que le fueran concedidos los títulos y sueldos de los diferentes cronistas, a lo que accedió el Rey Felipe $V$ por decreto de 25 de octubre de 1744, que planteaba la incorporación en la Academia de Historia de los títulos, empleos y sueldos de las crónicas vacantes y de las que fuesen vacando de futuro. ${ }^{23}$

Por eso cuando en 1750 falleció Miguel Herrero de Ezpeleta, Cronista Mayor de Indias desde 1736, la Real Academia de Historia acudió a Fernando VI en solicitud del título, que tras informe favorable del Consejo de Indias fue firmado por el Rey en Aranjuez el 7 de mayo de 1750, procediendo el Consejo a la expedición del nombramiento el 17 de mayo, y a la toma de posesión de la Academia el 23 de ese mes, después de pagar la media anata. ${ }^{24}$

No obstante, aún siendo notorio y público que Felipe $\mathrm{V}$ había concedido la futura a la Academia de la Historia, y conociendo también que la Academia de la Historia había solicitado el título a Fernando VI y que el Rey lo había firmado en mayo, aparecieron muchos interesados en el cargo, como bien decía en junio de 1750 Martín Sarmiento a Fernando José de Velasco. ${ }^{25}$ Uno de esos interesados era sin duda el bibliotecario mayor Juan de Santander, que en nombre de la Real Biblioteca recordó al rey que unos años antes, cuando se había producido la vacante por el fallecimiento de Salazar y Castro, el bibliotecario mayor -entonces Blas Nasarre- había señalado a Felipe $\mathrm{V}$ la conveniencia de que el empleo pasase a la Real Biblioteca y bajo la dirección del bibliotecario. ${ }^{26}$ Y Santander precisaba en su representación de junio de 1750 que las razones esgrimidas entonces subsistían aún, porque "los papeles y libros andan dispersos y se han perdido en poder de los cronistas; estos nada han trabajado más ha de un siglo". ${ }^{27}$

${ }^{23}$ Archivo de la Real Academia de la Historia. América. Papeles Varios. Leg. 9-4161. Decreto de 25 de octubre de 1744 incorporando a la RAH los oficios de cronistas generales y particulares.

24 Copia del registro de ese título de mayo de 1750 a favor de la Real Academia en de Indias (AGI). Indiferente, Leg. 448, L 48, fols. 74-76. Puede verse sobre el particular Nava Rodríguez, M. 1987. "La Real Academia de la Historia como modelo de unión formal entre el Estado y la cultura (1735-1792)". Cuadernos de Historia Moderna y Contemporánea 8: 127-155.

${ }^{25}$ Santos Puerto, J. 2010. "Cartas de Martín Sarmiento a Fernando José de Velasco". Grial: Revista galega de cultura 186: 55-63.

26 Las razones pueden resumirse así: Gregorio Mayans se postuló para ocupar la vacante y Juan de Ferreras, ya anciano, hizo lo mismo, apremiado por Nasarre, según criterio de Mayans en carta de 1751 enviada al nuncio Enríquez. Muerto Ferreras sin ocupar la vacante, se produjo esa petición de Nasarre a Felipe $\mathrm{V}$ que recuerda Juan de Santander a Fernando VI. (Mestre Sanchís, A. 1970. Historia, fueros y actitudes políticas: Mayans y la historiografía del XVIII: 381. Valencia: Publicaciones del Ayuntamiento de Oliva.

${ }^{27}$ Sarmiento, Martín. 1976. Epistolario Español, 2: 197. BAE. 
Acaso por esa circunstancia cambió el criterio del Rey, que para evitar enfrentamientos entre la Academia y la Biblioteca, decidió anular el nombramiento dado en mayo y designar a otra persona, ajena a las dos instituciones, como en parte hiciera Felipe $V$ cuando en 1736 lo había dado a Miguel Herrero. De hecho, esa debió ser idea inicial de Fernando VI, antes de que la Academia de la Historia le recordase el compromiso de su padre. $\mathrm{O}$ al menos eso parece desprenderse de la correspondencia de Sarmiento con Fernando de Velasco:

"Vacó la Crónica de Indias, y porque vale 200 doblones salieron a ellos muchos pretendientes, no obstante dicha futura, por decir que este Rey las había anulado. Sin pensar en eso se me hizo el envite por arriba. Resistíme tres veces en tres cartas". ${ }^{28}$

Sarmiento se sintió aliviado cuando supo que la Academia de la Historia había tomado posesión del título y pagado la media anata. Y cuando después tuvo conocimiento de que el Rey insistía en nombrarle para el empleo, contrariando el título ya registrado por el Consejo de Indias, volvió a escribir, como le dice a Velasco:

"Reclamé yo en mi respuesta, resistiéndome más que antes por ser averso a empleos contenciosos. Reclamó también el Consejo. $Y$ con razón. Pero ni sus razones ni mi resistencia han sido oídas. Y así el día 25 me hallé con aviso del Consejo de que el Rey persistía en que yo fuese cronista de Indias. Ahora no sé qué hacerme pues como miro los empleos sólo por donde queman, estoy desazonado sin poderlo remediar". ${ }^{29}$

Aunque la notificación que le hizo el Consejo de Indias tenía fecha de 25 de junio, el nombramiento había sido firmado por el Rey el día 13. Y antes de que el benedictino recibiese el aviso oficial, ya la noticia había corrido por Madrid. Y por Valencia, como muestra la correspondencia de Gregorio Mayans.

En efecto, el 20 de junio de 1750 Pingarrón señalaba a Mayans algo similar a lo referido por Sarmiento a Velasco, es decir que la Academia de la Historia había acudido al Consejo de Indias para que le despachara el título, conforme al decreto de Felipe $\mathrm{V}$ de 1744; que la Academia había pagado la media anata y había recibido el título y jurado el empleo; pero que después el Rey había concedido la plaza al padre Sarmiento, "Dicen que éste no le quiere -precisaba Pingarrón-y que se ha resistido a admitirlo". ${ }^{30}$

Y a la semana siguiente Pingarrón informaba de nuevo a Mayans: "Antes de ayer tuvo el P. Sarmiento el aviso de haberle nombrado el Rey por

${ }^{28}$ Santos Puerto, J. 2010: 60.

29 Ídem.

30 Mayans, G. 1987. Epistolario, VII. Mayans y Martínez Pingarrón. Transcripción, notas y estudio preliminar de Mestre, A. Oliva: Ayuntamiento de Oliva. Carta de 20 de junio de 1750. 
OCASIONES RECHAZÓ LAS OFERTAS DEL REY

cronista de Indias; lo admitirá sin duda". ${ }^{31}$ Sorprende esta última afirmación, pues Pingarrón escribe el mismo día que lo hacía Sarmiento a Fernando J. Velasco, señalándole que no sabía qué hacer.

Ese mismo día 27 de junio, enterado por la carta de Pingarrón citada, Mayans escribe a Blas Jover: "Extraña novedad ha sido la que me escriben sobre la plaza de cronista de Indias". Y Jover responde, el 4 de julio: "Amigo mío, más novedad que a Vm. ha hecho a la Academia de la Historia la provisión del $\mathrm{P}$. Sarmiento, pero a mí ninguna este suceso, ni los demás extravagantes que sucedan". ${ }^{32}$

La situación planteada, nombrando el Rey a Sarmiento después de que el Consejo de Indias hubiera dado el título a la Academia, puede calificarse de suceso extravagante, como decía Blas Jover. Pero no puede llamarse extravagante la elección de Sarmiento, pues venía teniendo una importante participación en el programa escultórico del palacio real, programa que, como he señalado antes, tenía un marcado carácter histórico y didáctico.

Ya señalamos antes que desde 1733 Sarmiento venía ejerciendo de cronista de la congregación benedictina. $Y$ otras circunstancias deben acaso apuntarse aquí para incidir en su amplios criterios históricos, como es el hecho de que en 1738 se hubiera solicitado a él y a Mayans la censura de la España Primitiva de Huerta; y que Valentí Gonzaga le hubiera pedido que pusiera en negro sobre blanco sus conocimientos sobre los poetas españoles, que daría lugar a la primera gran historia de la poesía española, que influyó decisivamente en la compilación y estudio de Thomas Antonio Sánchez, como él mismo explica en el Prólogo de su Colección de Poesías Castellanas anteriores al siglo XV.

Volvamos de nuevo al título de Cronista. Sarmiento no tenía interés en aquel empleo que lo exponía a la crítica cruzada de la Academia de la Historia y de la Real Biblioteca. Por eso decía a Fernando de Velasco que estaba desazonado con el nombramiento. Con José Luis Roche, amigo comerciante afincado en el Puerto de Santa María, debió ser igual de explícito. Aunque no conservamos el original del benedictino, la respuesta de Roche indica que Sarmiento le hizo saber que no estaba interesado ni en el sueldo ni en el

${ }^{31}$ Carta de 27 de junio de 1750, Ibídem.

${ }^{32}$ Mayans, G. 1995. Epistolario, XIII. Mayans y Jover. Transcripción, notas y estudio preliminar de Molas, P. Oliva: 327. Ayuntamiento de Oliva. La carta de Mayans, de 27 de junio. La respuesta de Jover. ibídem: 324. Allí se dice que la carta es de 4 de junio, pero se trata sin duda de un error, y esos dos párrafos de esta página 324 pertenecen a la carta de 4 de julio, que está más adelante, páginas 328329. El traspapelado es fácil de ver siguiendo el orden cronológico de lo que se dice sobre el cronista de Indias. Primero, la noticia de la que habla Jover, "la provisión del P. Sarmiento", no existía el día 4 de junio, porque el decreto del nombramiento fue dado en Aranjuez el día 13. Segundo, en la supuesta carta de 4 de junio, Jover responde a lo que comentará Mayans tres semanas después, el día 27 de junio. Sorprende que esta supuesta carta del 4 de junio aparezca fechada y firmada por Blas Jover. Supongo que se trata de un error en la transcripción. 
empleo, que él consideraba una carga. Parte de la respuesta del amigo Roche cabe exponerla aquí:

"Aunque embarazado con el correo de hoy, que ha sido largo -dice Roche- no quiero dejar la respuesta de su muy apreciable carta para otro día. Por ella se sirve confiarme el honor que quiere hacerle nuestro Rey, de Cronista General de las Indias, a que no condesciende VRma, cosa que aún teniendo yo la honra de conocer su prodigioso desinterés, me ha dejado asombrado. $Y$ no es para menos, pues apenas habrá en este mundo hombre alguno que ejecute (ni aún en sueños) lo que VRma hace muy despierto. ¿A dónde va a parar con dar de mano a 12.000 reales anuales? Con todo, no me hace fuerza, y hasta aquí tienen valimiento todas las razones de VRma y otras trescientas que se le ofrezcan. Pero para desechar el honor y la honra (que se aprecia más que la vida), y lo que es más, los favores de un monarca tan grande como el de España, ¿qué razones puede haber? Que por mirar a la Academia, a quien Felipe $V$ había concedido esta futura, no es disculpa. Lo primero, porque todos saben que VRma no lo ha pretendido, y lo segundo, porque aún dado el caso que estuviese en lo contrario, no pesa tanto el mal juicio pasajero de cuatro individuos que el bueno, firme y estable de muchos que conocen a VRma (...) Maula y carga llama VRma al empleo honorífico de Cronista General de las Indias. Y no contento con tan malos nombres se amenaza a sí propio con no llegar a viejo o con una vejez infelicísima si lo admite (...) si todos los cronistas hubiesen escrito nos enterraría la multitud de los libros. D. Luis de Salazar, hombre capaz de hacerlo, no dio plumada en el asunto. D. Antonio Solís, con solo un libro desempeñó su oficio y ganó fama para siempre. Con que venimos a parar en que no es carga ni maula, sino un bru espanta niños". ${ }^{33}$

Sarmiento sabía que una vez firmado ya por el Rey le era difícil rechazar el nombramiento. Pero en un último intento de ganar tiempo señaló que antes de aceptar necesitaba el permiso del general de su orden, lo que solicitó a primeros de julio expresando al general íñigo González Ferreras su poca disposición para aceptar el empleo. La respuesta del superior fue, sin embargo, inequívoca, ordenándole obedecer al Rey. ${ }^{34} \mathrm{Y}$ fue así como finalmente el 28 de julio de 1750 el Consejo de Indias canceló el título concedido a la Real Academia de la Historia y procedió a expedirlo a nombre de Martín Sarmiento, que el Rey firmó en el Buen Retiro el 1 de agosto.

El benedictino tomó posesión del cargo el día 12, y se dispuso a cargar con aquella maula después de haberse resistido cinco veces, como le decía a

${ }^{33}$ Real Academia de la Historia, Mss. 9/5762. Carta de Juan L. Roche, 31/06/1750. Acerca de la correspondencia entre Roche y Sarmiento puede verse Pacheco Albalate, M. 2004. Una visión del siglo XVIII: cartas del erudito Roche al benedictino Sarmiento. Puerto de Santa María: Ayuntamiento.

${ }^{34}$ López Peláez, A. 1895: 76 
OCASIONES RECHAZÓ LAS OFERTAS DEL REY

su amigo Felipe Colmenero. ${ }^{35}$ Habían pasado unos meses desde la aceptación cuando recibió carta de Francisco Roca, procurador general de los benedictinos en Roma, felicitándole por el nombramiento. La escasa disposición de Sarmiento para el empleo había variado poco:

"Aprecio la enhorabuena de Cronista de Indias -decía Sarmiento a Roca- pero no aprecio ni un comino el dicho empleo, pues se me ha dado como oficio de jornal, que a razón de lo que escribiere se me dará el sueldo. Ni quiero el sueldo ni el oficio, ni quiero escribir por dinero. Leer, estudiar y escribir por gratificación y que no se acorte la salud ha de ser con tiempo, a gusto y elección del sujeto y no por gustos de otros". 36

No debe tomarse como licencia poética el planteamiento de Sarmiento, pues algo parecido era lo que expresaba el título que se le había expedido. Alí se dice que en atención a su mérito y literatura el Rey le había nombrado el 13 de junio cronista de los reinos de las Indias para suceder a Miguel Herrero. Y que en calidad de tal cronista, debería proseguir la escritura de la historia de Indias, recopilando materiales para la claridad e inteligencia de lo sucedido en su descubrimiento y en otras cosas dignas de memoria. También tendría a su cargo el examen de lo que otros escribiesen sobre el particular.

Además de las honras y privilegios del cargo, se le asignaba un salario de doce mil reales anuales, que debería satisfacer el tesorero general en las fechas y plazos en que hacía los pagos de los consejeros de Indias "precediendo manifestar la parte de Historia que, como estáis obligado, en aquel año respectivamente hubiereis escrito, y llevando certificado de mi secretario, así de lo referido como de vuestra residencia en esta Corte". ${ }^{37}$

Ya vemos que para cobrar los sueldos anuales había que justificar qué era lo que se había escrito aquel año sobre la historia de Indias. Y por tanto no le faltaba algo de razón a Sarmiento cuando definía el empleo como oficio de jornal, pagadero en función de lo que se fuera escribiendo. Lo que no decía el benedictino -y sí decía el título- es que por expresa orden del Rey se le había eximido del pago de la media anata, concesión particularmente favorable para con el benedictino que no se había hecho con los cronistas anteriores: "declaro no debéis maravedíes algunos al derecho de la media anata por esta merced por haberme servido relevaros, con real orden mía de 20 del corriente, de lo que por esta causa os correspondía satisfacer". Esa fue, acaso, solicitud de Sarmiento al Rey para aceptar la vacante, ya que él

${ }^{35}$ Sarmiento, M. 1995. Epistolario: 465. Edición de Filgueira, J. y Fortes, M.J. Santiago de Compostela: Consello da Cultura Galega,

36 Santos Puerto, J. 2010. Correspondencia inédita... Carta a Roca, de 01/11/1750.

37 Título de Chronista General de los Reinos de Indias al Mtro. Fray Martín Sarmiento de la religión de San Benito. Archivo General de Indias. Indiferente, 448, L, 48. fols. 92-94. 
difícilmente podía hacerse cargo de pagar los 6.000 reales de la media anata cuando tenía previsto no cobrar los sueldos del empleo.

En 1796 apareció el primer tomo de las Memorias de la Real Academia de la Historia, que dedicó abundantes páginas a dar cuenta del "origen, progresos, y trabajos literarios" de la institución. El apartado IX trata de la "Historia de Indias", y comienza señalando parte de lo que ya conocemos, es decir que a pesar de la concesión de la futura de Felipe $V$ en 1744, la Real Academia no entró en posesión del cargo tras la muerte de Miguel Herrero, porque aunque el Consejo le había expedido el título, al mismo tiempo el Rey Fernando VI había conferido el empleo a Sarmiento, que lo ejerció hasta que fue nombrado para la abadía de Ripoll. Y después de transcribir el contenido del real decreto de 1755 de concesión del título a la Real Academia, en la citada Memoria se puntualiza: "Ignórase cómo cumplió su oficio el maestro Sarmiento en los cinco años que lo poseyó; lo cierto es que si algo trabajó o coordinó, no lo ha visto ni disfrutado hasta aquí la academia". ${ }^{38}$

Nosotros sí sabemos qué hizo Sarmiento en relación con el oficio de Cronista General de Indias durante los cinco años que mediaron entre su nombramiento y el de la Real Academia. Nada escribió sobre la historia de Indias y ningún documento manejó de los existentes en el Consejo. Si acaso pudiera entenderse como trabajo para el Consejo unos pocos pliegos, Sobre una descripción de la América, que entregó al Marqués de Valdelirios, consejero de Indias y encargado de señalar y fijar los nuevos límites y fronteras hispano-lusitanas en el Río de la Plata, tras el acuerdo de límites firmado en 1750 entre España y Portugal. Con ese trabajo, parecido al que había redactado y remitido algún tiempo antes para su amigo Gaspar de Urquizu, oidor de la audiencia de Lima, intentaba orientar a Valdelirios en la recogida de materiales históricos, geográficos, naturalistas y lingüísticos en cumplimiento de su misión americana. Pero cabe decir que ese trabajo no lo redactó tanto para el consejero de Indias cuanto para el Valdelirios contertulio y amigo.

De modo que puede decirse que Sarmiento poco hizo en relación con el oficio de cronista de Indias, pero también debe decirse que nada cobró durante el tiempo que fue titular del empleo, porque como le había escrito a su amigo Roche y después repitió al procurador benedictino en Roma, no quería el sueldo, ni aquel oficio que le obligaba a escribir por dinero sobre la Historia de las Indias desde el retiro de su celda, cosa incompatible con su manera de entender la historia, pues como muy bien recordaba uno de sus primeros biógrafos, el benedictino entendía que el historiador no podía escribir recluso entre cuatro paredes sobre la historia de tierras lejanas que jamás había visto,

${ }^{38}$ Real Academia de la Historia. 1796. Memorias de la Real Academia de la Historia. Tomo I: LXI. Madrid: Imprenta de Sancha. 
OCASIONES RECHAZÓ LAS OFERTAS DEL REY

sino que debería peregrinar y conocerlas, siguiendo el ejemplo de Herodoto y Polibio. $^{39}$

Y en buena medida es lo que hace Sarmiento cuando en mayo de 1754 se ausenta de la Corte para ir a recrearse a Pontevedra, pero no a conocer ni escribir de las Indias, sino de su tierra gallega, tarea a la que dedicará buena parte de su tiempo a partir de entonces, como puede verse en el diario que escribe sobre el viaje. ${ }^{40}$

\section{NOMBRAMIENTO DE ABAD DE RIPOLL Y RENUNCIA PROFETIZADA POR EL REY}

La antes citada Memoria de la Academia de la Historia señalaba que Sarmiento tuvo que dejar el empleo de Cronista cuando fue nombrado para la abadía de Ripoll, "por ser oficio que requiere precisa residencia en la Corte". Y efectivamente, como antes vimos, en el título de cronista de Indias se especificaba que para realizar los cobros debía entregarse certificado de la parte de historia escrita a lo largo del año, así como de la residencia en la corte, circunstancias que también figuran en los títulos dados a otros cronistas, ya que la residencia en la corte era obligación del cronista de Indias desde los tiempos de Felipe II. ${ }^{41}$

Llevaba el benedictino más de medio año en Galicia cuando en el Consejo de Indias se abrió un expediente para proveer de nuevo el cargo de cronista, por ausencia de la corte del titular. ${ }^{42}$ Sin embargo en esos últimos meses de 1754 no se tomó ninguna resolución para apartarle del cargo, ya fuese porque el Rey no autorizó el cese o porque el conflicto era menor pues el monje no recibía ni reclamaba la asignación estipulada para el cronista. Desconocemos si Sarmiento tuvo noticias del expediente. Lo que sabemos es que no hizo nada por volver a Madrid.

En el mes de junio de 1755 acompañó a su hermano Xavier, comisario de marina, en la visita de los puertos gallegos, y cuando en julio regresó a

${ }^{39}$ García Tato, I. y Valdés Hansen, F. 2003. Vida y Obra del R.P.M. fr. Martín Sarmiento: 293. Santiago de Compostela: CSIC-Instituto P. Sarmiento de Estudios Gallegos.

40 Sarmiento, M. 1950. Viaje a Galicia (1754-1755). Edición y notas de Sánchez Cantón, J. y Pita Andrade, J.M. Santiago: CSIC-Instituto P. Sarmiento de Estudios Gallegos.

${ }^{41}$ Recopilación de Leyes de Indias. Libro II, Título 12, ley $1^{\mathrm{a}}$. El título de Miguel Herrero de Ezpeleta señalaba que debería residir en la Corte, "o donde residiere el Consejo", en prevención de que la Corte se asentase fuera de Madrid, como había ocurrido con ocasión de la estancia de Felipe V en Sevilla entre 1729 y 1733.

${ }^{42}$ AGI, Indiferente, leg. 1520. Expedientes sobre nombramiento de Cronistas, Cosmógrafos de Indias y otros empleos del Consejo. Cf. Nava Rodríguez, M.T. 1987: 147. Y también Nava Rodríguez, M.T. 1990. "Bases y objetivos de una historia general del Nuevo Mundo: el cargo de cronista mayor de las Indias entre 1755 y 1764". Cuadernos de Historia Moderna 10: 103-120. 
Pontevedra se encontró con una carta de Andrés de Otamendi, fechada en Madrid el 4 del mes anterior, señalándole que el Rey le había nombrado abad del monasterio de Ripoll, nombramiento que ya se había hecho efectivo en la cámara de Castilla. Sarmiento responde el día 7 aceptando el nombramiento aunque advirtiendo que necesita obtener previamente licencia del general de la orden.

El permiso del general Vítores de Lasanta le llegó desde Asturias el día 24, pero en la corte no esperaron a la respuesta y en la Gaceta del día 22 de julio había ya aparecido la noticia: "se ha servido SM nombrar al maestro fr. Martín Sarmiento para la abadía claustral benedictina del real monasterio de Sta. María de Ripoll, en el principado de Cataluña".

Por esas fechas había recibido carta del confesor Rávago, poniéndole al tanto de cómo se había gestado el nombramiento y señalándole su compromiso para ayudarle en los gastos necesarios para la obtención de las bulas, influyendo en el ánimo del Rey para que le fuesen abonados los sueldos del empleo de cronista de Indias, aún cuando no hubiese ejercido el oficio. $^{43}$

Al poco tiempo le llegó comisión del nuncio en Madrid para tomar posesión y juramento de la abadía, cosa que hizo el 11 de agosto ante el obispo de Tuy. Ese mismo día le escribe a su amigo Medinasidonia dándole las gracias por haber influido en la decisión del Rey, y a la vez quejándose de que se hubiese conchabado con el confesor Rávago para sacarle de su retiro gallego.

"Si alguno me quisiese censurar, tenga $V^{a} E x^{a}$ por cierto que le he de echar la culpa mancomunado con el $\mathrm{P}$. Confesor, pues tan de veras se han mancomunado los dos para sacarme de mi retiro. Cuando, tan de repente, y sin pensar en ello, me vi con el aviso formal del Sr. Otamendi y sin aviso previo, ni con carta, a lo menos concomitante de $V^{a} E x^{a}$ ni del Ilmo. P. Confesor, y supe que el Rey, Dios le guarde, me había dado por sí mismo dicha Abadía de Ripoll, sin consulta ni propuesta de la Cámara, hice la reflexión siguiente: (...) la voluntad de los reyes en cosas inferiores no se mueve, por lo común, sin algún inferior influjo, que informe y que incline. (...) tardé poco en asentir a que el influjo de $V^{a} E x^{a}$ y del Ilmo. P. Confesor había sido el primero y último determinativo de la voluntad del Rey". ${ }^{44}$

${ }^{43}$ No dudo -le decía el confesor Rávago- que se necesite gasto considerable, y más para quien como VRma. ha de ser heredado o desposeído en vida de todo lo que tuviere. Para algún alivio de este perjuicio procuraré dos cosas: primera, que el Rey, como dueño que es de su hacienda, mande que se le paguen los sueldos de Cronista, haya o no haya trabajado en ello; segundo, aliviarle de las pensiones que podrían ponerle, según costumbre, o en todo en lo que se pudiere, cuando hayan vacado algunas; y, en fin, no omitiré cuanto yo pudiere en el caso. (Santos Puerto, J. 2002:192).

44 Sarmiento, M. 1995. Cartas al duque de Medinasidonia: 105. Es carta fechada el 11/08/1755. 
OCASIONES RECHAZÓ LAS OFERTAS DEL REY

Habían pasado pocos días cuando de nuevo escribía a Medinasidonia y le hacía saber que su nombramiento había sido mal recibido por algunos: "si la abadía se hubiese dado a otro, que la desease, todos le colmarían de enhorabuenas, y aplaudirían su aceptación. Yo he sido tan desgraciado, que casi todos me han colmado, y por escrito, de enhoramalas, censuras y reprehensiones. Entrando a la parte enemigos, amigos e indiferentes". ${ }^{45}$ Conocida en Madrid la aceptación de la abadía, el Consejo de Indias elevó consultas al Rey para traspasar el cargo de cronista a la Real Academia, ya que el nombramiento de Sarmiento para la abadía exigía residencia en Ripoll y no era compatible con la residencia en la corte y continuar de cronista. Fernando VI firmó el decreto correspondiente y el título para la Real Academia en San Lorenzo, a 18 de octubre. ${ }^{46}$

El 20 de octubre Sarmiento salió de Pontevedra para Madrid, a donde no pudo llegar hasta el 27 de noviembre. Allí se encontró con inconvenientes no previstos para hacerse cargo de la abadía. Primero, supo que no había sido eximido de pagar la media anata, como en un principio creía, y necesitaba más dinero; segundo, que ya no podía contar con el apoyo prometido por Rávago, porque había sido destituido como confesor del Rey a primeros de noviembre; y tercero, acaso derivado de lo anterior, que el comerciante catalán con quien algunos amigos habían concertado un préstamo para desempeñar las bulas, se había echado atrás a pesar del crecido interés del $16 \%$ pactado.

Comenzó entonces a pensar en la posibilidad de renunciar, pero sorpresivamente le llegaron noticias de que el 17 de noviembre el Papa le había preconizado abad, al mismo tiempo que al arzobispo de Sevilla y al obispo de Jaca. ${ }^{47}$ Le comentan que el Banco Real aportó el dinero de las bulas y que él tendrá que desempeñarlas cuando lleguen a Madrid. Supone entonces que las gestiones iniciales de Rávago, y las posteriores del ministro Wall, habían surtido efecto y que el Rey había dado orden para que se le anticipara el dinero del desempeño de las bulas a cuenta de los sueldos de cronista.

De acuerdo con lo dispuesto en las constituciones benedictinas vigentes en la época, aquellos que fuesen promovidos a empleos y dignidades fuera de la orden dejaban de pertenecer a ella una vez que el Papa diese el plácet al nombramiento. También tenían que dejar los libros, alhajas y pertenencias a la casa de profesión, y en caso de llevarlos consigo sería siempre haciendo inventario y tasación, otorgando escritura de venta por

45 Ibídem, pág. 107. Es carta de 08/09/1755.

46 Real Provisión a la Real Academia de la Historia, dándole título de cronista general perpetuo de los reinos de Indias. AGI, Indiferente, 448, Leg. 49, fols.48-50.

47 "Participa la noticia -le dice a su hermano Xavier el 24 de diciembre- a nuestro P. Abad de Lérez, y a todos los parientes, amigos y conocidos; y que ya soy abad de Ripoll, por la gracia del Rey, y del Papa; y que deseen conmigo, que sea por la gracia de Dios, que es la principal, sin bulas, ni media annata; y Gratis etiam quo ad scripturam". 
el importe tasado a favor del monasterio. ${ }^{48}$ Fue por eso que a primeros de 1756 el abad de San Martín, Fulgencio Ojeda, había reunido al consejo para proceder a realizar el inventario y la tasación ya que Sarmiento tenía intención de llevar consigo sus libros. ${ }^{49}$

Por las navidades de 1755 ya estaban las bulas en Madrid, pendientes de ser desempeñadas. Sarmiento conoce que en realidad el dinero no lo había anticipado el Rey sino un gallego afincado en Roma, Francisco Bermúdez, admirador del benedictino a pesar de no haberse tratado personalmente. Enterados de la situación, algunos amigos intentaron aportar soluciones: Roche, desde el Puerto de Santa María, le ofreció el dinero que necesitase a un bajo interés del 8\%; su hermano Xavier y otros familiares intentaron también contribuir, pero Sarmiento dijo a todos que no, a la espera de saber si la propuesta de Wall en relación con los sueldos de cronista se hacía finalmente realidad. ${ }^{50}$

Pero llegó el mes de febrero y la oferta de Wall no prosperaba. Desde El Ferrol recibió carta de su amigo Perea, que le ofrecía 60.000 reales sin rédito, a pagar cuando pudiese. Su hermano insiste en contribuir al desempeño de las bulas, pero él comienza a pensar en renunciar: "Estoy aburrido con vivir en Madrid y sin apetito a vivir en Ripoll y sólo suspiro por ir a coger mixtos de la historia natural a esos países patrios" ${ }^{51}$

Le retiene el embarazo de no saber cómo podía tomarlo el Rey. A últimos de marzo decide presentar un memorial explicando al monarca las razones por las que desea renunciar. Con el acuerdo del Rey, presentó formalmente la renuncia el día 6 de mayo de 1756, mediante escrito dirigido a Andrés de Otamendi para que éste lo hiciese llegar a la Cámara. Las principales razones expuestas, tanto en el memorial al Rey como en la renuncia enviada al Consejo a través de Otamendi, hacen referencia a la rigurosidad del clima, a los muchos pleitos que debe atender el abad, que no le dejarán tiempo para leer. ${ }^{52}$ La renuncia se publicó en la Gaceta de Madrid:

${ }^{48}$ Constituciones de la Congregación... Lib. II. Cap. 14 no 8.

${ }^{49}$ Libro de Actas del Consejo de este Monasterio de San Martín de Madrid. Biblioteca Nacional de Madrid, Mss.13284, fol. 357. Acta del consejo de 2 de enero de 1756. Sus compañeros de hábito le encargaron al propio Sarmiento la realización del inventario y la tasación de su biblioteca.

50 "Esta oferta se me hizo -explica a Roca- sin soñar yo en pedirla ni en mostrarme acreedor a los dichos mil doblones. En virtud de la palabra del ministro, me vi también embarazado para no deber tomar yo otras providencias que me serían fáciles para desempeñar las bulas". (Santos Puerto, J. 2010. Correspondencia inédita..., carta de 7/6/1756).

${ }^{51}$ Sarmiento, M. 1995. Epistolario: 54.

${ }^{52}$ El memorial y la renuncia fueron publicados por Monteagudo, H. 2003. "A renuncia de Martín Sarmiento a Abadía de Ripoll (1756). Duas cartas inéditas", GRIAL. Revista Galega de Cultura 159: 77-83. Aunque el memorial no tiene fecha, sabemos que fue presentado al rey el 27 de marzo de 1756, como explicó Sarmiento a Francisco Roca el 7 de junio de 1756. La renuncia fue presentada a Hispania Sacra, LXV

Extra II, julio-diciembre 2013, 231-252, e-ISSN: 1988-4265, doi: 10.3989/hs.2013.041 
OCASIONES RECHAZÓ LAS OFERTAS DEL REY

"El Rey ha concedido licencia al M. Fr. Martín Sarmiento para renunciar la abadía claustral benedictina del Real Monasterio de Ripoll y la ha conferido al a D. Fr. Joseph de Oriol y Tord, paborde del mismo monasterio". 53

Muchos amigos no entendieron la renuncia. Por eso decía a Medinasidonia: "El día 6 de marzo hice y firmé la formal renuncia de la abadía y la remití a la Cámara (...) Con la aceptación sólo quise hacer el gusto del Rey. Pero habiendo conseguido su real beneplácito, para hacer el mío en la renuncia, se palpa que no necesito persuasiones para hacer mi verdadero gusto (...) según las muchas desazones que ya me había ocasionado la abadía, me consideraba metido en una tinaja de vinagre antes del feliz instante en que conseguí la licencia del Rey para renunciarla. Doy infinitas gracias a Dios por todo, y porque ya me he librado de aquel martirio, que me había amenazado sería eterno". 54 Tampoco lo entendieron algunos familiares. Por eso explicaba a su hermano Xavier: "Rávago creía que yo aceptaría la abadía y después renunciaría. Así me lo dijo él mismo. Oí que el Rey había dicho no la tomará, no la tomará. Y me alegro, pues ya habrá conocido que salió profeta-rey". ${ }^{55}$

Poco tiempo después de la renuncia formal recibió carta del procurador Roca, en la que le señalaba la inquietud de Francisco Bermúdez por el cobro del dinero que había aprontado en Roma para las bulas. Sarmiento contestaba a Roca: "dígale que aunque renuncié la abadía no renuncié el ser hombre de bien, agradecido, y el ser enemigo de trampas pecuniarias". Le explica también que la palabra dada por Wall todavía está en pie, y que los 1000 doblones del empleo de cronista aún no se han cobrado y que el abad que se nombre deberá pagar las bulas, por lo que "solo falta el que la Cámara acabe de arreglar los méritos de los pretendientes". Y finaliza: "por mi aceptación quedé desnudo de todo útil y empleo ad intra y ad extra. Por mi renuncia, he quedado como el alma de Garibay, ni tampoco sé cómo quedo, si fraile, si abad, si clérigo o capacho, etc. Así hasta que me digan cómo quieren que quede, me estoy estando, y sólo me atormenta la desconfianza que tienen los que me han favorecido". ${ }^{56}$

Cuando Sarmiento salió para Galicia en mayo de 1754 había dejado inacabado un escrito que llamaba Pensamientos Crítico-Botánicos. Lo retomó después de renunciar a la abadía, y allí anotó algunas circunstancias relacionadas con el nombramiento y la renuncia. Por eso sabemos que efectivamente las bulas se pagaron con los beneficios de la abadía y que el Rey le eximió de la media anata, aunque el benedictino precisaba: "por librarme de impertinencias hice renuncia formal a últimos de marzo de abadía,

Otamendi el 6 de mayo, como aparece en el documento publicado por Monteagudo y como confirma el propio Sarmiento en la carta citada anteriormente.

${ }^{53}$ Gaceta de Madrid, 6 de julio de 1756: 216.

54 Sarmiento, M. 1995. Cartas al Duque de Medinasidonia, carta de 10/05/1756.

55 López Peláez, A. 1895: 82.

56 Santos Puerto, J. 2010. Correspondencia inédita: 350. 
bulas, rentas con exclusiva de pensión alguna. De este modo me quedé monje particular y en mi plena libertad. $Y$ aunque de los frutos caídos se pagaron las bulas, y el Rey mandó que me indemnizaran de otros gastos, el hecho es que de ocho a nueve mil reales que me ocasionó dicha abadía, no he percibido un maravedí siquiera. Esto he sacado de que hayan querido sacarme de mi celda, sin soñar yo en eso". 57

Liberado de las ataduras de la abadía de Ripoll, su situación en Madrid era un tanto anómala, ya que con la aceptación había dejado de pertenecer a San Martín. La situación persistirá hasta el capítulo de 1757 en que será de nuevo readmitido. A partir de entonces en la cabeza de Sarmiento está de continuo la idea de volver a Galicia. Una razón le retiene, su librería, para la que no encuentra comprador y no quiere dejar en Madrid, como le explica en 1763 a su amigo Hiebra, abad de Lérez. "El no saber qué hacer de 6.500 espantajos de mis libros me aterra. Si voy, ha de ser para no volver. Llevarlos es quimera. Dejarlos in perpetuum no es razón. Darlos no quiero. Sólo queda el arbitrio de venderlos, y hace muchos años que estoy pensando en eso. Esto es, en venderlos todos, imponer el capital a censo a favor de esta mi casa e irme a comer los réditos a Lérez, hasta morir". ${ }^{58}$

Al no poder ir para Pontevedra, Sarmiento trajo Galicia a su celda y a su mente y comenzó a reivindicar la cultura popular de los hombres y mujeres de su tierra gallega y a centrar su mirada en la recuperación, la dignificación y la enseñanza de su lengua. Es por esas manifestaciones precursoras, consideradas ridículas y disparatadas en su tiempo, por las que en buena medida las letras gallegas le rindieron tributo y reconocimiento en 2002.

\section{BIBLIOGRAFÍA CITADA}

Allegue Aguete, P. 1993. A filosofía ilustrada de fr. Martín Sarmiento. Vigo: Xerais.

Álvarez Barrientos, J. y Herrero, C. 2002. Sistema de adornos del Palacio Real de Madrid. Madrid: Conmemoraciones Culturales.

Constituciones de la Congregación de nuestro glorioso padre san Benito de España e Inglaterra. Madrid: Viuda de Melchor Álvarez.

Costa, A. y Álvarez, M. 2002. Martín Sarmiento. La educación de la niñez y de la juventud [textos]. Madrid: Biblioteca Nueva.

Filgueira Valverde, J. 1981. Ideas y sistema de la historia en Fr. Martín Sarmiento. Madrid: Real Academia de la Historia.

García Tato, I. y Valdés Hansen, F. 2003. Vida y Obra del R.P.M. fr. Martín Sarmiento. Santiago de Compostela: CSIC-Instituto P. Sarmiento de Estudios Gallegos.

57 Sarmiento, M. Pensamientos crítico-botánicos. Cito por el texto manuscrito guardado en la Biblioteca Nacional de Madrid, Colección Dávila, X, 2ª , § 264.

${ }^{58}$ Santos Puerto, J. 2010. Correspondencia inédita: 354. 
MARTÍN SARMIENTO, EL BENEDICTINO GALLEGO QUE EN REPETIDAS

OCASIONES RECHAZÓ LAS OFERTAS DEL REY

Jurado Jiménez, D. 2011. "El diario como instrumento de autoformación e investigación”. Qurriculum 24: 173-200.

López Peláez, A. 1895. El Gran Gallego. La Coruña: Andrés Martínez.

Maté Sadornil, L. 2003. "Silos dentro de la Congregación Benedictina de Valladolid en los siglos XVI-XVIII", en Silos, un milenio, vol. 2, 297-320. Burgos: Universidad de Burgos.

Mayans, G. 1987. Epistolario, VII. Mayans y Martínez Pingarrón. Transcripción, notas y estudio preliminar de Mestre, A. Valencia: Ayuntamiento de Oliva.

Mayans, G. 1995. Epistolario, XIII. Mayans y Jover. Transcripción, notas y estudio preliminar de Molas, P. Valencia: Ayuntamiento de Oliva.

Mestre Sanchís, A. 1970. Historia, fueros y actitudes políticas: Mayans y la historiografía del XVIII. Valencia: Ayuntamiento de Oliva.

Monteagudo, H. 2002. Martín Sarmiento, Sobre a lingua galega. Antoloxía. Vigo: Galaxia.

Monteagudo, H. 2003. "A renuncia de Martín Sarmiento a Abadía de Ripoll (1756). Duas cartas inéditas". GRIAL 159: 77-83.

Muniaín Ederra, S. 2000. El Programa escultórico del Palacio Real de Madrid y la Ilustración Española. Madrid: FUE.

Nava Rodríguez, M. 1987. "La Real Academia de la Historia como modelo de unión formal entre el Estado y la cultura". Cuadernos de Historia Moderna y Contemporánea 8: 127-155.

Nava Rodríguez, M.T. 1990. "Bases y objetivos de una historia general del Nuevo Mundo: el cargo de cronista mayor de Indias entre 1755 y 1764". Cuadernos de Historia Moderna 10: 103-120.

Pacheco Albalate, M. 2004. Una visión del siglo XVIII: cartas del erudito Roche al benedictino Sarmiento. Puerto de Santa María: Ayuntamiento.

Pardo de Guevara, E. 2002. Fr. Martín Sarmiento, el amador de la verdad (1695-1772). A Coruña: Diputación Provincial.

Pensado Tomé, J.L. 1960. Fray Martín Sarmiento. Sus ideas lingüísticas. Oviedo: Universidad de Oviedo.

Pensado Tomé, J.L. 1972. Fr. Martín Sarmiento, testigo de su siglo. Salamanca: Universidad de Salamanca.

Real Academia de la Historia. 1796. Memorias de la Real Academia de la Historia. Tomo I. Madrid: Imprenta de Sancha.

Reguera, A.T. 2006. La obra geográfica de Martín Sarmiento. León: Universidad de León.

Rumeu de Armas, A. 2001. La Real Academia de la Historia. Madrid: Real Academia de la Historia. 
Santamarina, A. (coord). 2002. Frei Martín Sarmiento. Día das letras galegas 2002. Santiago de Compostela: Universidad de Santiago.

Santos Puerto, J. 2002. Martín Sarmiento: Ilustración, educación y utopía en la España del s. XVIII. A Coruña: Fundación Barrié de la Maza

Santos Puerto, J. 2010. "Acerca de la naturaleza y de la patria del P. Sarmiento". Sarmiento 14: 125-131.

Santos Puerto, J. 2010. "Cartas de Martín Sarmiento a Fernando José de Velasco". Grial: Revista galega de cultura 186: 55-63.

Santos Puerto, J. 2010. "Correspondencia inédita y otras contribuciones para ampliar el Epistolario de Martín Sarmiento". Cuadernos de Estudios Gallegos 123: 319-356.

Sarmiento, M. 1950. Viaje a Galicia (1754-1755). Edición y notas de Sánchez Cantón, J. y Pita Andrade, J.M. Santiago: CSIC-Instituto P. Sarmiento de Estudios Gallegos.

Sarmiento, M. 1995. Cartas al Duque de Medinasidonia, edición de Santos Puerto, J. Ponferrada: Instituto de Estudios Bercianos.

Sarmiento, M. 1995. Epistolario. Edición de Filgueira, J. y Fortes, M.J. Santiago de Compostela: Consello da Cultura Galega.

Varela Oriol, C. 2011. "Martín Sarmiento y las bibliotecas de la congregación benedictina de Valladolid". Hispania 237: 121-152.

Velasco Moreno, E. 2000. La Real Academia de la Historia en el siglo XVIII: una institución de sociabilidad. Madrid: Centro de Estudios Políticos y Constitucionales.

VV.AA. 1995. Estudos adicados a Fr. Martín Sarmiento. Santiago de Compostela: Instituto de Estudios Gallegos Padre Sarmiento y CSIC.

VV.AA. O Padre Sarmiento e o seu tempo. 1997. Santiago de Compostela: Universidad de Santiago y Consello da Cultura Galega.

Zaragoza Pascual, E. 1984. Los Generales de la Congregación de San Benito de Valladolid (1701-1801). Silos: Abadía de Silos.

Zaragoza Pascual, E. 1992. "Cronistas generales de la congregación de San Benito de Valladolid". Boletín de la Real Academia de la Historia 189: 89126. 